\title{
Article
}

\section{Discrimination of fresh frozen non- tumour and tumour brain tissue using spectrochemical analyses and a classification model}

Bury, Danielle Elizabeth, Medeiros-De-morais, Camilo De lelis, Martin, Francis L, Lima, Kassio M.G., Ashton, Katherine M., Baker, Matthew J. and Dawson, Timothy P.

Available at http://clok.uclan.ac.uk/30582/

Bury, Danielle Elizabeth, Medeiros-De-morais, Camilo De lelis ORCID: 00000003-2573-787X, Martin, Francis L ORCID: 0000-0001-8562-4944, Lima, Kassio M.G., Ashton, Katherine M., Baker, Matthew J. and Dawson, Timothy P. (2020) Discrimination of fresh frozen non-tumour and tumour brain tissue using spectrochemical analyses and a classification model. British Journal of Neurosurgery, 34 (1). pp. 40-45. ISSN 0268-8697

It is advisable to refer to the publisher's version if you intend to cite from the work. http://dx.doi.org/10.1080/02688697.2019.1679352

For more information about UCLan's research in this area go to http://www.uclan.ac.uk/researchgroups/ and search for <name of research Group>.

For information about Research generally at UCLan please go to http://www.uclan.ac.uk/research/

All outputs in CLoK are protected by Intellectual Property Rights law, including Copyright law. Copyright, IPR and Moral Rights for the works on this site are retained by the individual authors and/or other copyright owners. Terms and conditions for use of this material are defined in the policies page. 


\section{Discrimination of fresh frozen non-tumour and tumour brain tissue using spectrochemical analyses and a classification model}

Danielle Bury ${ }^{1}$, Camilo L M Morais ${ }^{1}$, Francis L Martin ${ }^{1}$, Kássio M G Lima $^{2}$,

Katherine M Ashton ${ }^{3}$, Matthew J Baker ${ }^{4}$, Timothy P Dawson ${ }^{3 *}$

${ }^{1}$ School of Pharmacy and Biomedical Sciences, University of Central

Lancashire, Preston PRI 2HE, UK

${ }^{2}$ Biological Chemistry and Chemometrics, Institute of Chemistry, Federal University of Rio Grande do Norte, Natal 59072-970, Brazil

${ }^{3}$ Department of Neuropathology, Royal Preston Hospital, Lancashire Teaching

Hospitals NHS Trust, Sharoe Green Lane, Preston PR2 9HT, UK

${ }^{4}$ WestCHEM, Department of Pure and Applied Chemistry, Technology and Innovation

Centre, University of Strathclyde, Glasgow, G11RD, UK

*Corresponding Author: Professor Timothy Dawson, Department of

Neuropathology, Royal Preston Hospital, Lancashire Teaching Hospitals NHS Trust, Sharoe Green Lane, Preston PR2 9HT, UK; Telephone: 01772522140; Fax:

01772522181; Email: Timothy.dawson@1thtr.nhs.uk

Emails: deb11@doctors.org.uk, cdlmedeiros-de-morai@ uclan.ac.uk, flmartin@uclan.ac.uk, kassiolima@gmail.com, katherine.ashton@lthtr.nhs.uk, timothy.dawson@1thtr.nhs.uk, matthew.baker@strath.ac.uk.

The authors declare no competing interests.

This project was funded by Rosemere Cancer Foundation.

All authors have contributed equally.

Total word count: 4150 


\begin{abstract}
Introduction: In order for brain tumours to be successfully treated, maximal resection is beneficial. A method to detect infiltrative tumour edges intraoperatively, improving on current methods would be clinically useful. Vibrational spectroscopy offers the potential to provide a handheld, reagent-free method for tumour detection. Purpose: This study was designed to determine the ability of both Raman and Fourier-transform infrared (FTIR) spectroscopy towards differentiating between normal brain tissue, glioma or meningioma.

Method: Unfixed brain tissue, which had previously only been frozen, comprising normal, glioma or meningioma tissue was placed onto calcium fluoride slides for analysis using Raman and attenuated total reflection (ATR)-FTIR spectroscopy. Matched haematoxylin and eosin slides were used to confirm tumour areas. Analyses were then conducted to generate a classification model.

Results: This study demonstrates the ability of both Raman and ATR-FTIR spectroscopy to discriminate tumour from non-tumour fresh frozen brain tissue with $94 \%$ and $97.2 \%$ of cases correctly classified, with sensitivities of $98.8 \%$ and $100 \%$ respectively. This decreases when spectroscopy is used to determine tumour type. Conclusion: The study demonstrates the ability of both Raman and ATR-FTIR spectroscopy to detect tumour tissue from non-tumour brain tissue with a high degree of accuracy. This demonstrates the ability of spectroscopy when targeted for a cancer diagnosis. However, further improvement would be required for a classification model to determine tumour type using this technology, in order to make this tool clinically viable.
\end{abstract}

Key Words: Brain tumours, Classification model, Intraoperative diagnosis, Neurosurgery, Spectrochemical analyses 


\section{Introduction}

Brain tumours account for 3\% of all tumours diagnosed annually, with incidence rates increasing approximately $15 \%$ over the last decade ${ }^{1}$. Whilst they comprise a small proportion of all cancers diagnosed per year, the difficulty of complete removal of the tumour is inherent. High-grade tumours can be infiltrative with up to $75 \%$ of tumour resections thought to leave behind viable tumour ${ }^{2}$. Current techniques include the use of 5-aminolevulinic acid (5-ALA), a fluorescent compound to fluoresce tumour cells to enable the surgeon to visualise them more easily. This allows real-time feedback and does not rely on repeat intraoperative imaging ${ }^{3,4}$. A tool that could either improve, or work in conjunction with 5-ALA could prove useful to neurosurgeons, improving resection rates further and thus, hopefully, disease-free survival.

Vibrational spectroscopic techniques have been in use for many years, including two forms: Raman and attenuated total reflection Fourier-transform infrared (ATR-FTIR) spectroscopy. These are complimentary techniques producing results based upon vibrations within the chemical bonds of the interrogated sample. Studies on many tumour types comprising both tissue and biofluids, have shown promising results, and use a combination of both ATR-FTIR and Raman spectroscopy, with an ability to detect tumour from non-tumour cases ${ }^{5-18}$. Both Hands et. al. and our group have demonstrated separation of patients with and without primary brain tumours and metastatic lesion using blood serum and plasma with high sensitivities and specificities ${ }^{19-21}$.

Much of the current tissue-based work has been performed on formalin-fixed paraffin-embedded (FFPE) tissue. This presents a challenge, as even with dewaxing, the paraffin present may still interfere with spectra and hence results ${ }^{22,23}$. It has also 
been shown to vary depending on the substrate upon which the tissue is placed ${ }^{24}$. Previous studies have demonstrated the ability to differentiate low-grade and highgrade gliomas, meningiomas, and metastatic tumours, as well as producing a database of paediatric tumours to produce a classification model ${ }^{25,26}$. Differentiation of metastatic brain tumours has proven more challenging as results found some tumour types overlapped, for example adenocarcinomas, though there were points of differentiation identified in tumours of differing phenotype ${ }^{27,28}$. New studies from Desroches et. al. have demonstrated the use of a hand held Raman probe intraoperatively obtaining an accuracies of $84-87 \%$ when differentiating tumour from non tumour brain tissue ${ }^{29,30}$.

No studies have yet been done using fresh frozen tissue to differentiate different types of adult primary brain tumours. Whilst frozen tissue also has its own complications, the closer tissue is to its natural fresh state, the more relatable the results become ${ }^{22}$. This novel study therefore aims to determine the ability of both ATR-FTIR and Raman spectroscopy to classify non-tumour brain from gliomas and meningiomas using fresh frozen tissue in order to reduce the signal received from tissue fixation. To the authors' knowledge this is the first study performed using fresh frozen tissue, comparing both Raman and ATR-FTIR spectroscopy on adult brain tumours. If successful, results from this study have the potential to open the door towards intraoperative use of spectroscopy to delineate tumour from non-tumour brain tissue. This would provide a major advance in the intraoperative diagnosis of brain tumours. 


\section{Methods}

Ninety-six cases of fresh frozen brain tissue comprising primary brain tumours both gliomas of varying grades and meningiomas, along with normal brain were selected from the Brain Tumour North West tissue bank, with ethical approval (NRES14/EE/1270). This tissue has been retrieved from the patient and then snap frozen on arrival within the histopathology department. Frozen sections are cut and allowed to defrost prior to spectral acquisition. This tissue was chosen for analysis as it has not previously been formalin-fixed and therefore is closest to fresh tissue allowable given the number of cases tested. The cases used in the study are shown in Table 1 below, categorised by tumour type.

Ten- $\mu$ m-thick frozen sections were placed onto $25 \times 25 \times 1 \mathrm{~mm}$ Raman-grade calcium fluoride $\left(\mathrm{CaF}_{2}\right)$-coated slides (Cyrstan Limited). A matched 4- $\mu$ m-thick section stained with haematoxylin and eosin $(\mathrm{H} \& \mathrm{E})$ was then cut to allow viable tumour areas to be marked and confirmed. Following this, spectrochemical measurements were performed on the unstained samples using both Raman and ATRFTIR spectroscopy, focussed on the viable tumour areas.

\section{Raman spectroscopy}

Spectra were taken from 20-25 sampling points within the tumour tissue area using a Horiba Jobin-Yvon LabRAM HR800 spectrometer over 1800-400 cm-1 wavenumbers. An air-cooled CLDS point mode diode $785 \mathrm{~nm}$ laser with a single edge filter (cut off to $100 \mathrm{~cm}^{-1}$ ) and an output power of $300 \mathrm{~mW}$. This was done with a confocal hole of $100 \mu \mathrm{m}$ at a grating of $300 \mathrm{gr} / \mathrm{mm}$ and a $\times 50$ objective. For each spectrum, 2 accumulations each over 30 seconds were acquired. 


\section{ATR-FTIR Spectroscopy}

The ATR-FTIR spectroscopy measurements were performed on an Agilent Cary-600 Series FTIR spectrometer. Measurements were taken in transmission mode with 32 co-added scans over a range of 4000-400 $\mathrm{cm}^{-1}$ and a resolution of $4 \mathrm{~cm}^{-1}$. A background scan was taken prior to each sample with the same settings. Twenty sampling points were selected within each viable tumour area.

\section{Computational analysis}

Data collection and manipulation was performed within a MATLAB R2014b environment (MathWorks Inc., USA) using PLS Toolbox 7.9.3 (Eigenvector Research Inc., USA) with specimens first assigned to training, validation and test groups using the Kennard-Stone algorithm (see Table 2), where $70 \%$ of samples were placed into training and $15 \%$ each into validation and test groups.

Pre-processing using Savitzky-Golay smoothing followed by multiplicative scatter correction (MSC), baseline correction, and vector normalization were performed. The spectra were cut from $1800-500 \mathrm{~cm}^{-1}$ [see Supplementary Information (SI) Figures S1 and S5)]. Following on from this, principal component analysis with linear discriminant analysis (PCA-LDA) or quadratic discriminant analysis (PCAQDA), and genetic algorithm with LDA (GA-LDA) or quadratic discriminant analysis (GA-QDA) were performed in order to determine the best analytical method ${ }^{31}$. The training samples were used for model construction and the test set for the final classification evaluation. The validation group was used to prevent overfitting, once the model parameters are optimized according to the classification performance of this data set, making it sure that the training fitting performance is in accordance with the validation response. The optimum number of variables for GA-LDA/QDA was performed based on the average risk $G$ of misclassification in the validation set ${ }^{32}$. The 
GA routine was carried out during 40 generations with 80 chromosomes each.

Crossover and mutation probabilities were set to $60 \%$ and $10 \%$, respectively.

Moreover, the algorithm was repeated three times, starting from different random initial populations. The best solution (in terms of the fitness value) was employed. LDA and QDA were employed to the PCA scores and GA selected variables based on a Mahalanobis distance calculation between the classes ${ }^{32}$.

\section{Results}

\section{Raman Spectroscopy}

From the 96 cases, 1911 spectra were collected. During pre-processing 30 spectra were removed due to poor quality, observed by a Hotelling $\mathrm{T}^{2}$ versus $\mathrm{Q}$ residuals test. As in Table 2, tumours were classified by type rather than grade. Following preprocessing there were 159 spectra in class 1, 666 in class 2 and 1056 in class 3. Firstly, comparison was done between normal and tumour tissue, grouping both meningiomas and gliomas together (Figure 1, Table 3). This demonstrates that $94 \%$ of the cases were correctly classified as either tumour or non-tumour brain tissue, with a sensitivity of $98.8 \%$ and specificity of $41.7 \%$.

Following on from this the model was tested to determine if it could identify normal from meningioma from glioma (Figure S2 and Table 4). When asked to determine tumour by type the overall classification accuracy fell to $63.1 \%$. Normal brain tissue was still detected with an accuracy of over $90 \%$. Comparisons between each individual group are shown in the supplementary material.

\section{ATR-FTIR Spectroscopy}

The process was then repeated for ATR-FTIR spectroscopy. From the 96 cases, 1919 spectra were collected; again during pre-processing 38 spectra were removed due to 
poor quality, observed by a Hotelling $\mathrm{T}^{2}$ versus $\mathrm{Q}$ residuals test. Spectra were divided as above. Following pre-processing there were 159 spectra in class 1, 666 in class 2 and 1056 in class 3 . As for the Raman spectra, firstly, normal was compared to tumour (meningioma and glioma) with GA-QDA providing the best results, with a classification accuracy of $97.2 \%$ (Figure S7, Table 5). The sensitivity was $100 \%$ and specificity $66.7 \%$.

When comparing if the classification model could correctly identify normal versus meningioma versus glioma the accuracy fell to $79.2 \%$, (Figure 2 and Table 6) however was still above that achieved with the Raman spectroscopy (63.1\%). FTIR also gave higher accuracy results when comparing tumour to no tumour, $97.7 \%$ compared to $94 \%$.

\section{Discussion}

The ability of vibrational spectroscopic techniques to detect brain tumours with both blood components ${ }^{5-8,19-21}$ and formalin-fixed tissue ${ }^{25,28}$ has been previously demonstrated with high accuracy levels. Studies using fresh frozen brain tissue are few and far between, with one study within the paediatric field showing an ability to detect different tumour types and a second trialling a hand held Raman machine intraoperatively slowly moving forward $26,29,30$. This study aimed to compare both Raman and ATR-FTIR spectroscopy using fresh tissue, which had previously only been frozen, in order to determine which provided the most accurate classification results as a precursor to developing a tool for intraoperative detection of primary brain tumours. We have shown that as compared to normal brain tissue, ATR-FTIR and Raman spectroscopy can both detect normal from tumour tissue with a high degree of accuracy (97.7\% and 94\%, respectively). However, when asked to determine tumour 
type, the accuracy of both techniques drops (79.2 and 63.1\%, respectively). FTIR spectroscopy was however, considerably higher than Raman, perhaps demonstrating it is better placed to differentiate between the tumour types. The accuracy does though remain greatly below that offered by a conventional intraoperative smear diagnosis and thus would require improvement in order to be a clinically diagnostic tool. Though, these rates would allow for intraoperative delineation of tumour versus normal. Importantly, the sensitivity when comparing normal to tumour is high (87.1$100 \%$ ), meaning we are not over diagnosing tumours. The specificities are lower, though in this situation where a surgeon is aware of the presence of a tumour, high sensitivity remains the priority. One limitation of the study is the low number of 'normal' i.e. non-tumour cases tested $(n=8)$ as the majority of patients undergoing neurosurgery have a tumour. This is due to the low number of normal fresh frozen cases available within the brain bank. Therefore, if used clinically, a much larger number of normal samples is needed, the ability to test more background non-tumour brain is likely to improve the classification accuracy and specificity.

Moving forward, discussion with clinicians is also required to determine what is needed from an intraoperative diagnostic tool; i.e., cancer versus non-cancer or a defined tumour type and grade. The output from the machine for the surgeon then also needs to be defined. The use of a sound has previously been proposed, to allow the surgeon real time feedback of the spectroscopic output ${ }^{33}$. Easy to interpret, quick results would be required. Inter-user and inter-site consistency is also required. ${ }^{34}$

Overall, we have shown in this study and other research ${ }^{35}$ that spectroscopy may have potential in the diagnosis of intraoperative brain tumours; however, further work to improve classification would be required prior to clinical implementation. 
Further work to allow for comparison of primary to metastatic tumours would also prove useful in providing clinical useful information in real time.

Acknowledgements The authors would like to acknowledge the support from Rosemere Cancer Foundation and the Brain Tumour North West RTB and the Sidney Driscoll Neuroscience Foundation for their support. CLM Morais would like to thank CAPES-Brazil (grant 88881.128982/2016-01) for financial support. The authors' would also like to thank Kestra Dawson for her contribution with the graphical abstract.

Disclosure of Interests Statement The authors' declare no competing interests. 


\section{References:}

1. Cancer Research UK. Brain, other CNS and intracranial tumours statistics. Accessed 18/02/18, available from: http://www.cancerresearchuk.org/health-professional/cancerstatistics/statistics-by-cancer-type/brain-other-cns-and-intracranialtumours\#heading-Zero

2. Hollon T., Lewis S., Freudiger C. W., Xie S., Orringer D. A., Improving the accuracy of brain tumour surgery via Raman-based technology. Neurosurg Focus. 2016. 40(3): E9-25.

3. Hadjipanavis C. G., Widhalm G., Stummer W., What is the Surgical Benefit of Utilizing 5-ALA for Fluorescence-Guided Surgery of Malignant Gliomas? Neurosurgery 2015. 77(5): 663-673.

4. Galli R., Uckermann O., Temme A., Leipnitz E., Meinhardt M., Koch E., Schackert G., Steiner G., Kirsch M., Assessing the efficiency of coherent antiStokes Raman scattering microscopy for the detection of infiltrating glioblastoma in fresh brain tissue. J Biophotonics 2017. 10(3):404-414.

5. Owens G. L., Gajjar K., Trevisan J., Fogarty S. W., Taylor S. E., Da Gama-Rose B., Martin-Hirsch P. L., Martin F. L., Vibrational biospectroscopy coupled with multivariate analysis extracts potentially diagnostic features in blood plasma/serum of ovarian cancer patients. $J$. Biophotonics 2014. 7(3-4):200-209.

6. Gajjar K., Trevisan J., Owens G., Keating P. J., Wood N. J., Stringfellow H. F., Martin-Hirsch P. L., Martin F. L., Fourier-Transform infrared spectroscopy coupled with a classification machine for the analysis of blood plasma or serum: a novel diagnostic approach for ovarian cancer. Analyst 2013. 138(14):3917-3926.

7. Backhaus J., Mueller R., Formanski N., Szlama N., Meerpohl H.-G., Eidt M., Bugert P., Diagnosis of breast cancer with infrared spectroscopy from serum samples. Vib. Spectrosc. 2010. 52(2):173-177.

8. Ollesch J., Heinze M., Heise H. M., Behrens T., Bruning T., Gerwert K., It's in your blood: spectral biomarkers candidates for urinary bladder cancer from automated FTIR spectroscopy. J Biophotonics 2014. 7(34):210-221.

9. Bergholt M. S., Zheng W., Lin K., Ho K. Y., Teh M., Yeoh G. K., So J. B., Huang Z., Raman endoscopy for in vivo differentiation between benign and malignant ulcers in the stomach. Analyst 2010. 135(12):3162-3168.

10. Bergholt M. S., Zheng W., Ho K. Y., Teh M., Yeoh K. G., So J. B., Shabbir A., Huang Z., Fibre-Optic Raman spectroscopy probes gastric carcinogenesis in vivo at endoscopy. J Biophotonics 2013. 6(1):49-59.

11. Mitchell A. L., Gajjar K. B., Theophilou G., Martin F. L., Martin-Hirsch P. L., Vibrational Spectroscopy of biofluids for disease screening or diagnosis: translation from the laboratory to a clinical setting. Journal of Biophotonics 2014. 7(3-4):153-165.

12. Krishna C. M., Prathima N. B., Malini R., Vadhiraja B. M., Bhatt R. A., Fernandes D. J., Kushtagi P., Vidyasagar M. S., Kartha V. B., Raman spectroscopy studies for diagnosis of cancers in human uterine cervix. Vib. Spectrosc. 2006. 41(1):136-141.

13. Gallwas J., Turk L., Friese K., Dannecker C., Optical coherence tomography as a non-invasive imaging technique for preinvasive and 
invasive neoplasia of the uterine cervix. Ultrasound Obstet. Gynecol. 2010. 36(5):624-629.

14. Barr H., Kendall C., Hutchings J., Bazant-Hegemark F., Shepherd N., Stone N., Rapid endoscopic identification and destruction of degenerating Barrett's mucosal neoplasia. Surgeon 2011. 9(3):119-123.

15. Kendall C., Day J., Hutchings J., Smith B., Shepherd N., Barr H., Stone N., Evaluation of Raman probe for oesophageal cancer diagnostics. Analyst 2010. 135(12):3038-3041.

16. Lui H., Zhao J., McLean D., Zeng H., Real-time Raman spectroscopy for in vivo skin cancer diagnosis. Cancer Res. 2012. 72(10):2491-2500.

17. Zhao J., Lui H., McLean D. I., Zeng H., Integrated real-time Raman system for clinical in vivo skin diagnosis. Skin Res. Technol. 2008. 14(4):484-492.

18. Patel I. I., Trevisan J., Singh P. B., Nicholson C. M., Gopala Krishnan R. K., Matanhelia S. S., Martin F. L., Segregation of human prostate tissues classified high-risk (UK) versus low risk (India) for adenocarcinoma using Fourier-transform infrared or Raman microspectroscopy coupled with discriminant analysis. Anal. Bioanal. Chem. 2011. 401(3):969-982.

19. Hands J. R., Dorling K. M., Abel P., Ashton K. M., Brodbelt A., Davis C., Dawson T., Jenkinson M. D., Lea R. W., Walker C., Baker M. J., Attenuated total reflection fourier transform infrared (ATR-FTIR) spectral discrimination of brain tumour severity from serum samples. $J$. Biophotonics 2014. 7(3-4);189-199

20. Hands J. R., Clemens G., Stables R., Ashton K., Brodbelt A., Davis C., Dawson T. P., Jenkinson M. D., Lea R. W., Walker C., Baker M. J., Brain tumour differentiation: rapid stratified serum diagnostics via attenuated total refection Fourier-transform infrared spectroscopy. J Neurooncol. 2016. 127(3):463-472

21. Bury D., Morais, C. L. M., Paraskevaidi M., Ashton K. M., Dawson T. P., Martin F. L. Spectral classification for diagnosis involving numerous pathologies in a complex clinical setting: A neuro-oncology example. Spectrochim. Acta A: Mol. Biomol. Spectrosc. 2019. 206: 89-96.

22. O'Faolain E., Hunter M., Byrne J., Kellehan P., McNamara M., Byrne H., Lyng F., A Study Examining the Effects of Tissue Processing on Human Tissue Sections using Vibrational Spectroscopy. Vib. Spectrosc. 2005. 38(1-2):121-127.

23. Huang Z., McWilliams A., Lam S., English J., McLean D. I., Lui H., Zeng H., Effect of formalin fixation on the near-infrared Raman Spectroscopy of normal and cancerous human bronchial tissues. Int. J. Oncol. 2003. 23(3):649-655.

24. Fullwood L. M., Griffiths D., Ashton K., Dawson T., Lea R. W., Davis C., Bonnier F., Byrne H. J., Baker M. J., Effect of substrate choice and tissue type on tissue preparation for spectral histopathology by Raman microspectroscopy. Analyst 2014. 139(2):446-454.

25. Gajjar K., Heppenstall L. D., Pang W., Ashton K. M., Trevisan J., Patel I. I., Llabjani V., Stringfellow H. F., Martin-Hirsch P. L., Dawson T., Martin F. L., Diagnostic segregation of human brain tumours using Fourier transform infrared and/or Raman spectroscopy coupled with discriminant analysis. Anal. Methods 2012. 6(5): 89-102 
26. Auner A. W., Kast R. E., Rabah R., Poulik J. M., Klein M. D., Conclusions and data analysis: a 6-year study of Raman spectroscopy of solid tumours at a major pediatric institute. Pediatr. Surg. Int. 2013. 29(2):129-140.

27. Krafft C., Shapoval L., Sobottka S. B., Geiger K. D., Schackert G., Salzer R., Identification of primary tumors of brain metastases by SIMCA classification of IR spectroscopic images. Biochim. Biophys. Acta 2006. 1758(7);883-891.

28. Bury D., Faust G., Paraskevaidi M., Ashton K. M., Dawson T. P., Martin F. L. Phenotyping Metastatic Brain Tumours Applying Spectrochemical Analyses: Segregation of Different Cancer Types. Anal. Lett. 2019. 52(4):575-587.

29. Desroches J., Jerymn M., Mok K., Lemieux-Leduc C., Mercier J., St-Arnaud K., Urmey K., Guiot M-C., Marple E., Petrecca K., Leblond F., Characterization of a Raman spectroscopy probe system for intraoperative brain tissue classification. Biomed. Opt. Express 2015. 6(7):2380-2397.

30. Desroches J., Jerymn M., Pinto M., Picot F., Tremblay M.-A., Obaid S., Urmey K., Trudel D., Soulez G., Guiot M.-C., Wilson B. C., Petrecca K., Leblond F., A new method using Raman spectroscopy for in vivo targeted brain cancer tissue biopsy. Sci. Rep. 2018. 8(1):1792-1802.

31. Lima K. M. G., Gajjar K. B., Martin-Hirsch P. L., Martin F. L., Segregation of Ovarian Cancer Stage Exploiting Spectral Biomarkers Derived from Blood Plasma or Serum Analysis: ATR-FTIR Spectroscopy Coupled with Variable Selection Methods. Biotechnol. Prog. 2015. 31(3):832-839.

32. Siqueira L. F. S., Araujo Junior R. F., Antunes de Araujo A., Morais C. L. M., Lima K. M. G., LDA vs. QDA for FT-MIR prostate cancer tissue classification. Chemometr. Intell. Lab. Syst. 2017. 162:123-129.

33. Stables R., Clemens G., Butler H. J., Ashton K. M., Brodbelt A., Dawson T. P., Fullwood L. M., Jenkinson M. D., Baker M. J., Feature driven classification of Raman spectra for real-time spectral brain tumour diagnosis using sound. Analyst 2016. 142(1):98-109.

34. Morais C. L. M., Paraskevaidi M., Cui L., Fullwood N. J., Isabelle M., Lima K. M.G., Martin-Hirsch P. L., Sreedhar H., Trevisan J., Walsh M. J., Zhang D., Zhu Y. G., Martin F. L., Standardization of complex biologically derived spectrochemical datasets. Nat. Protoc. 2019. 14(5):1546-1577.

35. Bury D., Morais C. L. M., Ashton K. M., Dawson T. P., Martin F. L., Ex Vivo Raman Spectrochemical Analysis Using a Handheld Probe Demonstrates High Predictive Capability of Brain Tumour Status. Biosensors 2019. 9(2):49; https://doi.org/10.3390/bios9020049. 
Table 1 Tumour samples selected for analysis, broken down by tumour type and WHO grade.

\begin{tabular}{|l|c|c|c|c|c|c|}
\cline { 2 - 7 } \multicolumn{1}{c|}{} & $N$ & $\begin{array}{c}\text { WHO } \\
\text { Grade 1 }\end{array}$ & $\begin{array}{c}\text { WHO } \\
\text { Grade 2 }\end{array}$ & $\begin{array}{c}\text { WHO } \\
\text { Grade 3 }\end{array}$ & $\begin{array}{c}\text { WHO } \\
\text { Grade 4 }\end{array}$ & No Grade \\
\hline All Cases & 96 & 25 & 11 & 14 & 33 & 5 \\
\hline Normal brain & 8 & N/A & N/A & N/A & N/A & N/A \\
\hline Gliomas & 54 & 1 & 6 & 11 & 33 & 3 \\
\hline Meningiomas & 34 & 24 & 5 & 3 & N/A & 2 \\
\hline
\end{tabular}


Table 2 Number of samples within the training, validation and test groups based on the application of the Kennard-Stone algorithm.

\begin{tabular}{|c|c|c|c|}
\hline Class & Training & Validation & Test \\
\hline Normal & 111 & 24 & 24 \\
\hline Meningioma & 466 & 100 & 100 \\
\hline Glioma & 739 & 158 & 159 \\
\hline
\end{tabular}


Table 3 Results for classification models for normal versus tumour (meningioma and glioma) using Raman spectroscopy. Highlighted in red is the best classification model.

\begin{tabular}{|c|c|c|c|c|}
\cline { 2 - 5 } \multicolumn{1}{c|}{} & PCA-LDA & PCA-QDA & GA-LDA & GA-QDA \\
\hline Accuracy (\%) & 93.3 & 94.0 & 91.5 & 91.8 \\
\hline Sensitivity (\%) & 98.4 & 98.8 & 97.3 & 97.7 \\
\hline Specificity (\%) & 37.5 & 41.7 & 29.2 & 29.2 \\
\hline PPV (\%) & 94.4 & 94.8 & 93.7 & 93.7 \\
\hline NPV (\%) & 69.2 & 76.9 & 50.0 & 53.8 \\
\hline $\begin{array}{c}\text { Youden's } \\
\text { Index }\end{array}$ & 35.9 & 40.5 & 26.5 & 26.8 \\
\hline
\end{tabular}

\begin{tabular}{|c|c|c|c|}
\hline $\begin{array}{c}\text { Correct } \\
\text { Classification }(\%)\end{array}$ & Training & Validation & Test \\
\hline PCA-LDA & 85.5 & 91.4 & 93.3 \\
\hline PCA-QDA & 93.4 & 94.3 & 94.0 \\
\hline GA-LDA & 84.3 & 90.7 & 91.5 \\
\hline GA-QDA & 86.6 & 91.8 & 91.8 \\
\hline
\end{tabular}


Table 4 Results for classification models of normal versus meningioma versus glioma using Raman spectroscopy.

\begin{tabular}{|c|c|c|c|c|c|c|}
\cline { 2 - 7 } \multicolumn{1}{c|}{} & \multicolumn{2}{c|}{ Normal } & \multicolumn{2}{c|}{ Meningioma } & \multicolumn{2}{c|}{ Glioma } \\
\cline { 2 - 7 } \multicolumn{1}{c|}{} & $\begin{array}{c}\text { PCA- } \\
\text { LDA }\end{array}$ & GA-LDA & $\begin{array}{c}\text { PCA- } \\
\text { LDA }\end{array}$ & GA-LDA & $\begin{array}{c}\text { PCA- } \\
\text { LDA }\end{array}$ & GA-LDA \\
\hline $\begin{array}{c}\text { Accuracy } \\
(\%)\end{array}$ & 92.9 & 92.6 & 69.5 & 68.4 & 63.6 & 62.4 \\
\hline $\begin{array}{c}\text { Sensitivity } \\
(\%)\end{array}$ & 33.3 & 29.2 & 33.7 & 36.6 & 86.6 & 82.8 \\
\hline $\begin{array}{c}\text { Specificity } \\
(\%)\end{array}$ & 98.4 & 98.4 & 89.5 & 86.2 & 35.2 & 36.8 \\
\hline PPV (\%) & 66.7 & 63.6 & 64.2 & 59.7 & 62.7 & 62.6 \\
\hline NPV (\%) & 94.1 & 93.7 & 70.7 & 70.9 & 67.7 & 63.0 \\
\hline $\begin{array}{c}\text { Youden's } \\
\text { Index }\end{array}$ & 31.8 & 27.6 & 23.2 & 22.8 & 21.8 & 19.6 \\
\hline
\end{tabular}

\begin{tabular}{|c|c|c|c|}
\hline $\begin{array}{c}\text { Correct } \\
\text { Classification (\%) }\end{array}$ & Training & Validation & Test \\
\hline PCA-LDA & 59.0 & 62.5 & 63.1 \\
\hline GA-LDA & 66.1 & 68.9 & 61.7 \\
\hline
\end{tabular}


Table 5 Results of classification models for normal versus tumour (meningioma and glioma) using IR spectroscopy, with the best classification model highlighted in red.

\begin{tabular}{|c|c|c|c|c|}
\cline { 2 - 5 } \multicolumn{1}{c|}{} & PCA-LDA & PCA-QDA & GA-LDA & GA-QDA \\
\hline Accuracy (\%) & 92.1 & 87.1 & 94.1 & 97.7 \\
\hline Sensitivity (\%) & 98.1 & 87.1 & 100 & 100 \\
\hline Specificity (\%) & 12.5 & 87.5 & 16.7 & 66.7 \\
\hline PPV (\%) & 93.7 & 98.9 & 94.1 & 97.5 \\
\hline NPV (\%) & 33.3 & 33.9 & 100 & 100 \\
\hline $\begin{array}{c}\text { Youden's } \\
\text { Index }\end{array}$ & 10.6 & 74.6 & 16.7 & 66.7 \\
\hline
\end{tabular}

\begin{tabular}{|c|c|c|c|}
\hline $\begin{array}{c}\text { Correct } \\
\text { Classification }(\%)\end{array}$ & Training & Validation & Test \\
\hline PCA-LDA & 81.1 & 92.9 & 90.5 \\
\hline PCA-QDA & 93.3 & 86.2 & 84.5 \\
\hline GA-LDA & 91.5 & 95.4 & 92.9 \\
\hline GA-QDA & 96.7 & 97.9 & 97.2 \\
\hline
\end{tabular}


Table 6 Results of the classifcation models for normal versus meningioma versus glioma using IR spectroscopy.

\begin{tabular}{|c|c|c|c|c|c|c|}
\cline { 2 - 7 } \multicolumn{1}{c|}{} & \multicolumn{2}{c|}{ Normal } & \multicolumn{2}{c|}{ Meningioma } & \multicolumn{2}{c|}{ Glioma } \\
\cline { 2 - 7 } \multicolumn{1}{c|}{} & $\begin{array}{c}\text { PCA- } \\
\text { LDA }\end{array}$ & GA-LDA & $\begin{array}{c}\text { PCA- } \\
\text { LDA }\end{array}$ & GA-LDA & $\begin{array}{c}\text { PCA- } \\
\text { LDA }\end{array}$ & GA-LDA \\
\hline $\begin{array}{c}\text { Accuracy } \\
(\%)\end{array}$ & 90.8 & 95.8 & 73.1 & 83.4 & 64.0 & 79.2 \\
\hline $\begin{array}{c}\text { Sensitivity } \\
(\%)\end{array}$ & 8.3 & 50.0 & 26.0 & 56.0 & 96.2 & 98.1 \\
\hline $\begin{array}{c}\text { Specificity } \\
(\%)\end{array}$ & 98.5 & 100 & 98.9 & 98.4 & 22.6 & 54.8 \\
\hline PPV (\%) & 33.3 & 100 & 92.9 & 94.9 & 61.4 & 73.6 \\
\hline NPV (\%) & 92.1 & 95.6 & 71.0 & 80.4 & 82.4 & 95.8 \\
\hline $\begin{array}{c}\text { Youden's } \\
\text { Index }\end{array}$ & 6.8 & 50.0 & 24.9 & 54.4 & 18.8 & 53.0 \\
\hline
\end{tabular}

\begin{tabular}{|c|c|c|c|}
\hline $\begin{array}{c}\text { Correct } \\
\text { Classification (\%) }\end{array}$ & Training & Validation & Test \\
\hline PCA-LDA & 62.8 & 61.7 & 64.0 \\
\hline GA-LDA & 83.1 & 84.0 & 79.2 \\
\hline
\end{tabular}




\section{Figure Captions}

Figure 1 Graphical representations of normal versus tumour (Meningioma and glioma) using Raman spectroscopy. (A) PCA-LDA, (B) PCA-QDA, (C) GA-LDA, (D) GA-QDA.

Figure 2 Graphical representations of normal versus tumour (meningioma and glioma) using IR spectroscopy. (A) PCA-LDA, (B) PCA-QDA, (C) GA-LDA, (D) GA-QDA. 